\title{
Impact of lighting arrangements and illuminances on different impressions of a room
}

\author{
Ayşe Durak $^{\mathrm{a}}$, Nilgün Camgöz Olguntürk ${ }^{\mathrm{b}, *}$, Cengiz Yener ${ }^{\mathrm{b}}$, Dilek Güvençc, Yusuf Gürçınar ${ }^{\mathrm{a}}$ \\ ${ }^{a}$ Department of Interior Architecture, University of Cukurova, Adana, Turkey \\ ${ }^{\mathrm{b}}$ Department of Interior Architecture and Environmental Design, Faculty of Art, Design and Architecture, Bilkent University, 06800 Bilkent, Ankara, Turkey \\ ${ }^{\mathrm{c}}$ Department of Mathematics, Faculty of Science, Bilkent University, Ankara, Turkey
}

Received 27 February 2006; received in revised form 26 September 2006; accepted 27 October 2006

\begin{abstract}
This study explores whether different lighting arrangements (general lighting, wall washing and cove lighting) and different illuminances (500 and 320 lux) could affect the perception of the same space. An experimental study was conducted to investigate how the qualitative aspects of space (the impressions of a space) could be enhanced with lighting. Hundred participants were first asked to choose the most suitable lighting arrangement for each impression (clarity, spaciousness, relaxation, privacy, pleasantness and order) under the 500 lux illuminance. In the second stage, they were asked to compare the two illuminances (500 and 320 lux) for the lighting arrangement they selected in the first stage. There was a statistically significant relation between impressions and lighting arrangements, also between impressions and lighting levels. Thus, different lighting arrangements and lighting levels could be used to enhance the clarity, spaciousness, relaxation, privacy, pleasantness and order of a room. The results of this study found most suitable lighting arrangements with their illuminances for each impression, which is reported in the paper.
\end{abstract}

(C) 2006 Elsevier Ltd. All rights reserved.

Keywords: Perception; Artificial lighting; Lighting quality; Space quality; Ambience; Mood

\section{Introduction}

Interior design uses the manipulation of many interrelated elements including space, form, structure, lighting, texture and colour. Among these elements, lighting is often the one, which receives the least attention. Generally, designers concentrate on issues such as the form of space, colours, patterns of fabrics and the arrangement of furniture. The design of lighting is usually reduced to simple lighting criteria stated in quantitative terms. However, the same space might be perceived differently according to the colour temperature of light, the types and locations of light sources and the lighting arrangement, all of which are related to the qualitative aspects of lighting. These qualitative, rather than the quantitative aspects of

\footnotetext{
${ }^{*}$ Corresponding author. Tel.: + 90312 2902429; fax: + 903122664127.

E-mail address: onilgun@ bilkent.edu.tr (N. Camgöz Olguntürk).
}

the luminous environment are the main concerns in this study.

Several researchers have investigated psychological aspects of space lighting. Flynn [1-4] should be accepted as the pioneer in this field. In his works and those of his successors, the visual impressions are usually classified as clarity, spaciousness, relaxation, privacy, pleasantness and order. The works of Flynn [1-4], Mehrabian and Russel [5], İmamoğlu [6,7], Nuckolls [8], Erhardt [9], Tiller and Veitch [10], Sorcar [11], Smith [12,13], Steffy [14], Rea [15], Carmody and Sterling [16], Lou [17], Manav and Yener [18] are among the important studies regarding these aspects. Some of the findings of these researchers support each other, whereas others contradict. There is, as yet, no firm consensus among the lighting designers and researchers on the psychological aspects and impressions created by lighting.

This paper describes an experimental study done to investigate these qualitative aspects, namely clarity, spaciousness, 


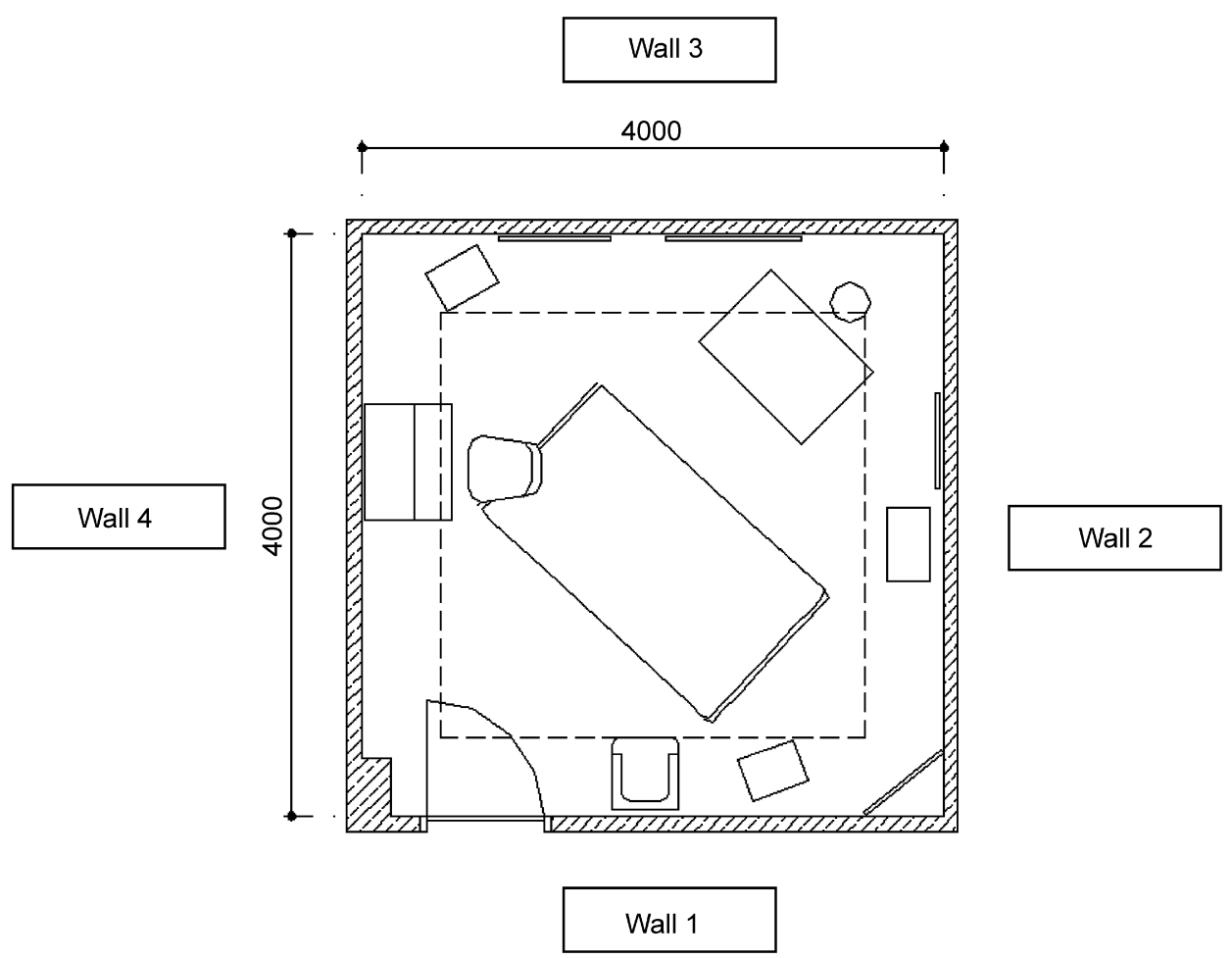

Fig. 1. Plan of the experiment room.

relaxation, privacy, pleasantness and order, to extend the data available in the literature.

\section{Hypotheses}

The experiment aimed to test the hypotheses below:

1. Different lighting arrangements effect impressions of people about a room.

2. Different illuminances of the same lighting arrangement effect impressions of people about a room.

\section{The experimental set-up}

In order to investigate the relations between lighting arrangements, illuminances and the perception of space, an experimental study was carried out and a special room was prepared.

The room had dimensions of $4 \mathrm{~m} \times 4 \mathrm{~m}$ with a height of $3 \mathrm{~m}$. There were no windows in the room; thus, any possible effects of daylighting were completely excluded. The floor was covered with gray (Munsell N5) terrazzo tiles with 0.2 luminous reflectance. The door was painted blue (Munsell 2.5B6/4) with 0.3 luminous reflectance. The ceiling was painted white (Munsell N9) with 0.79 luminous reflectance. The walls were painted peach (Munsell 10YR9/2) with 0.79 luminous reflectance.

For the experiment, the room was arranged in the form of a study room. In this arrangement, a table was located at one corner of the room designated as the observation table,

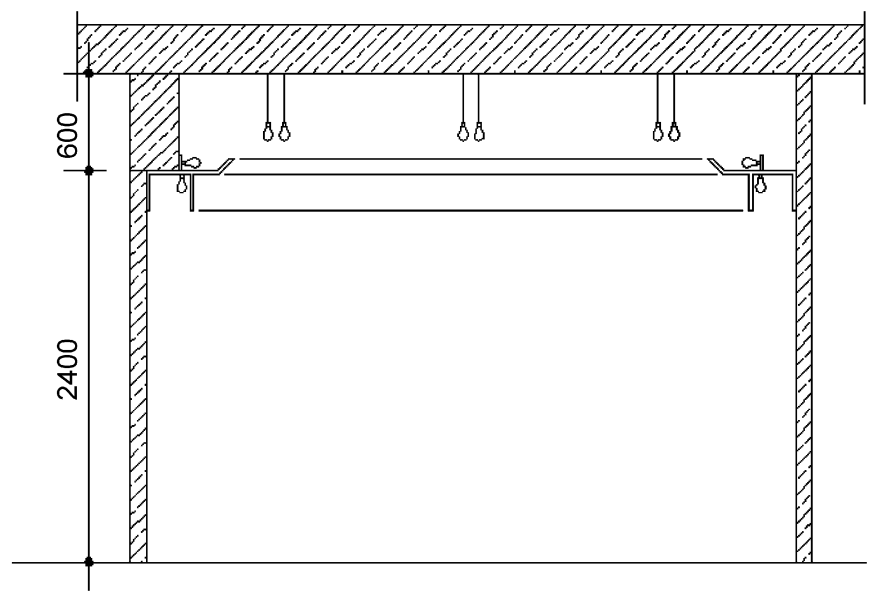

Fig. 2. Section of the experiment room.

where the participants evaluated the room. Figs. 1 and 2 show the plan and the section of the room, respectively.

Three different lighting arrangements, general (uniform) lighting, cove lighting and wall washing, were installed in the room (see Fig. 3). Each type of lighting was connected to two different circuits generating two different illuminances, 500 lux (high) and 320 lux (low), representing optimum and acceptable lower illuminances for general office activities by ISO 8995 [19], CIE Report No. 29 [20], Philips Lighting Manual [21] and IES Lighting Handbook [22]. Illuminances were determined according to the recommended values for general office tasks as the experiment room was arranged in the form of a study 


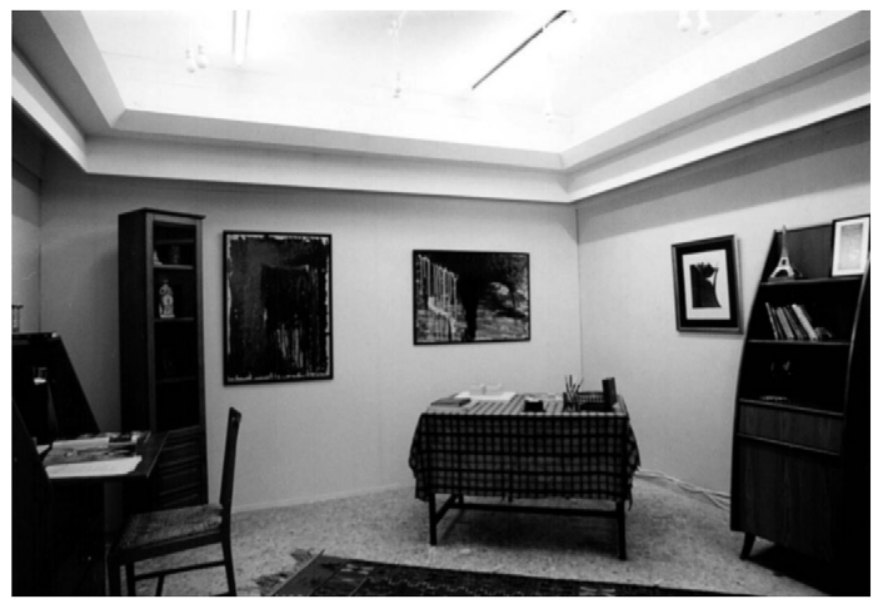

Fig. 3. View of the experiment room from the entrance.

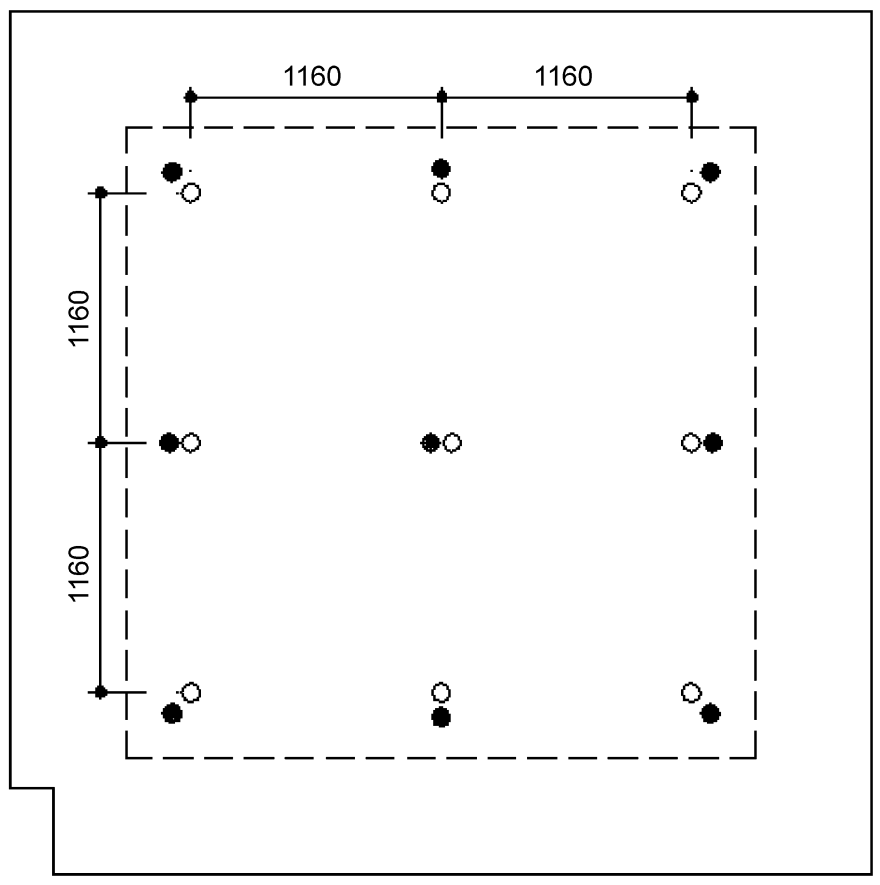

Fig. 4. Layout of the two circuits in general lighting.

room where such activities are likely to be carried out. The higher illuminance was 500 lux, corresponding to the illuminance recommended for general office activities [19-22]. The lower illuminance was 320 lux, the acceptable lower level of illumination for similar activities [19]. To obtain these illuminances, two independent electrical circuits were installed. The reason for not using a dimmer was to obtain two different lighting levels without changing the colour temperature of the light. In this way, the Correlated Colour Temperature (CCT) was kept constant. Illuminances were measured at a working plane, $800 \mathrm{~mm}$ high, at the centre of the room with a Minolta T-1 Illuminance meter. All the measurements were taken before the tests in the empty experiment room.

In all of the lighting arrangements, incandescent lamps were used, as these were the most widely used lamps in small size offices in Turkey. Philips Softone Standard A type bulbs, Colour Rendering Index (CRI) $(\mathrm{Ra})=100$ and $\mathrm{CCT}=2800 \mathrm{~K}$, were used to achieve a more diffused light distribution. Figs. 4-6 show the layout of the installed lamps for each lighting arrangement and for each illuminance.

To obtain general lighting, incandescent lamps were hung $300 \mathrm{~mm}$ from the ceiling with equal distance between them. The illuminance of 500 lux was obtained with the use of nine $100 \mathrm{~W}$ lamps, and 320 lux with the use of five $75 \mathrm{~W}$ and four $60 \mathrm{~W}$ lamps.

In wall washing, 500 lux level was obtained with the use of twenty-four $75 \mathrm{~W}$ and four $60 \mathrm{~W}$ lamps, and 320 lux with the use of twenty-four $60 \mathrm{~W}$ and four $40 \mathrm{~W}$ lamps.

In cove lighting, the same levels were obtained with the use of eight $75 \mathrm{~W}$ and twenty $60 \mathrm{~W}$ lamps for 500 lux, and four $60 \mathrm{~W}$ and twenty-four $40 \mathrm{~W}$ lamps for 320 lux.

Two switch boxes, each with three buttons were connected to the lighting systems. The switch boxes were named as " $\mathrm{H}$ " for high level (500 lux) and "L" for low level (320 lux).

The switch boxes were located on the observation table. On each switch box, the three lighting arrangements were indicated with their first letters, as $\mathrm{G}$ (general lighting), W (wall washing) and $\mathrm{C}$ (cove lighting). For wall washing and cove lighting, the lamps were installed as shown in Fig. 7. Fig. 8 shows the switch boxes.

Surface luminances of the experiment room were measured with Minolta LS-100 luminance meter. Walls were fairly uniformly illuminated. On each surface, four measurements were taken $200 \mathrm{~mm}$ away from each corner and one measurement was taken from the centre. Mean values of the five measurements were reported as the surface luminance. According to the luminance measurements, the ceiling was the most luminous surface under cove lighting $\left(76 \mathrm{~cd} / \mathrm{m}^{2}\right)$ and the four walls were the most luminous surfaces under wall washing $(55,61,65$ and $67 \mathrm{~cd} / \mathrm{m}^{2}$, with a mean value of $62 \mathrm{~cd} / \mathrm{m}^{2}$ ) (see Table 1 ). In all experiments, exactly the same bulbs were used, so, always a uniform lighting with the same CCT and with the same CRI were provided.

\section{Methodology: experimental procedure}

Hundred participants, 40 male and 60 female, took part in this study. They were all undergraduate students from the Department of Architecture at Çukurova University, Adana, Turkey. Their ages ranged from 18 to 27 -years old. None of the participants have taken any courses on lighting before.

Participants were admitted one at a time. Once they entered the experiment room, they were seated at the observation table. The experimental procedure was explained to them before they were asked to fill-in the questionnaire that was provided.

The questionnaire consisted of six questions about the impressions of clarity, spaciousness, relaxation, privacy, pleasantness and order. The questionnaire form is shown in Table 2. 


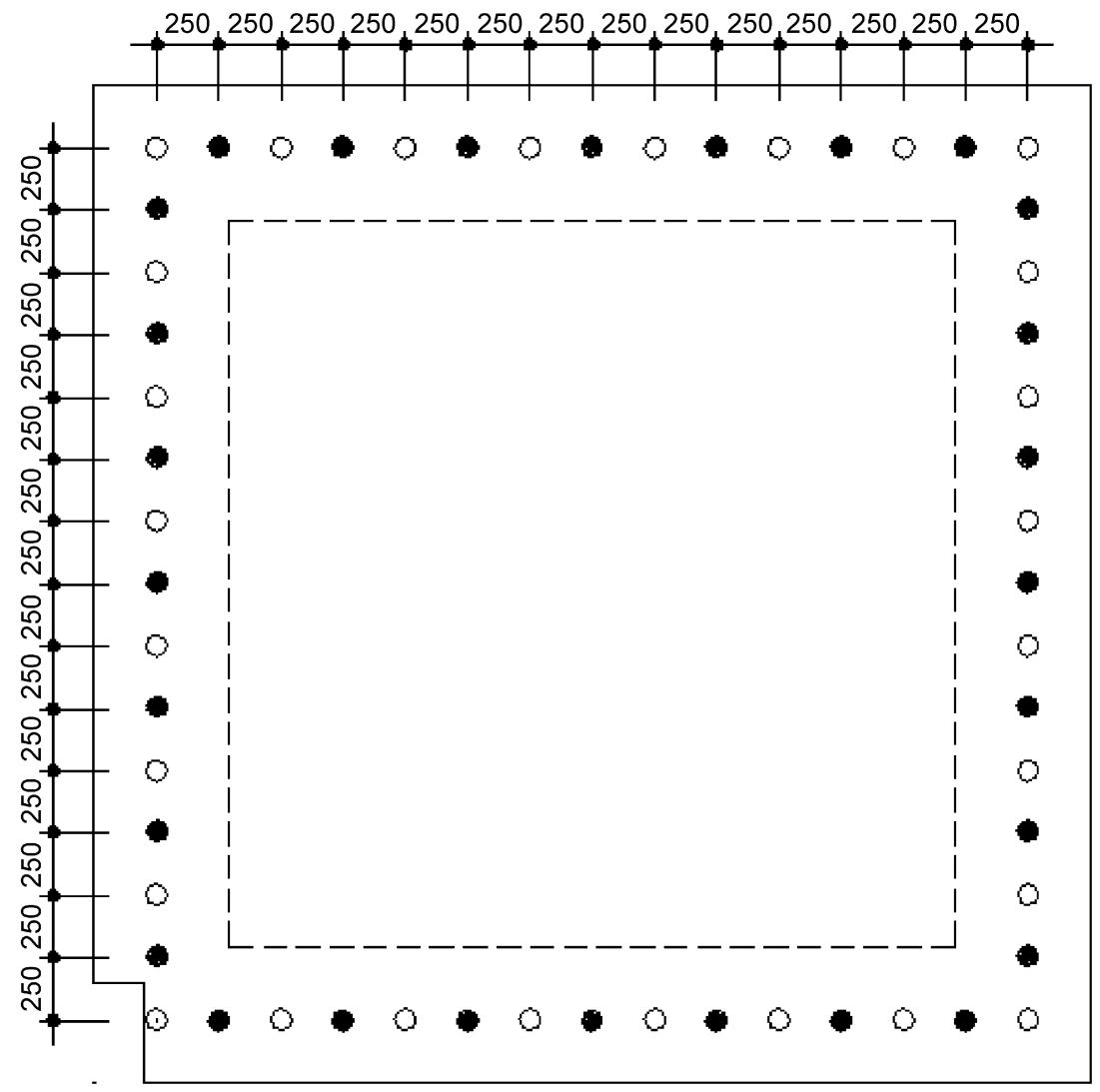

Fig. 5. Layout of the two circuits in cove lighting.

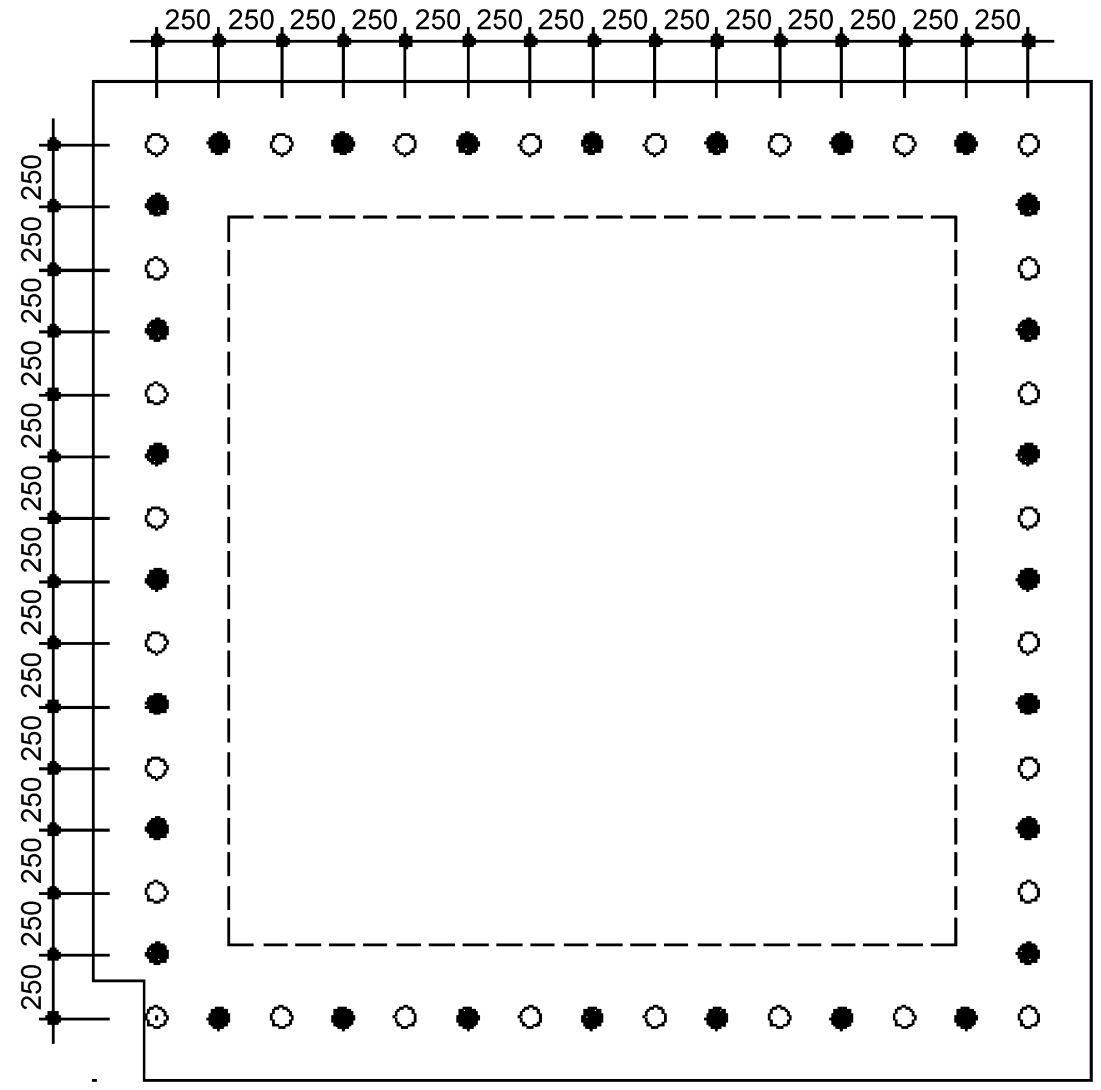

Fig. 6. Layout of the two circuits in wall washing. 


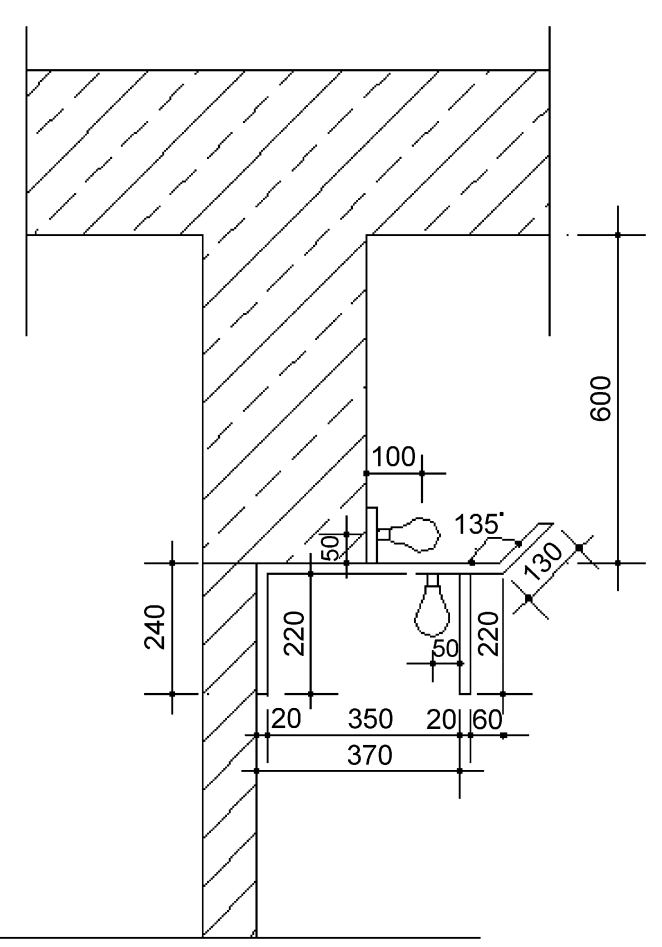

Fig. 7. Lamp installations of wall washing and cove lighting.

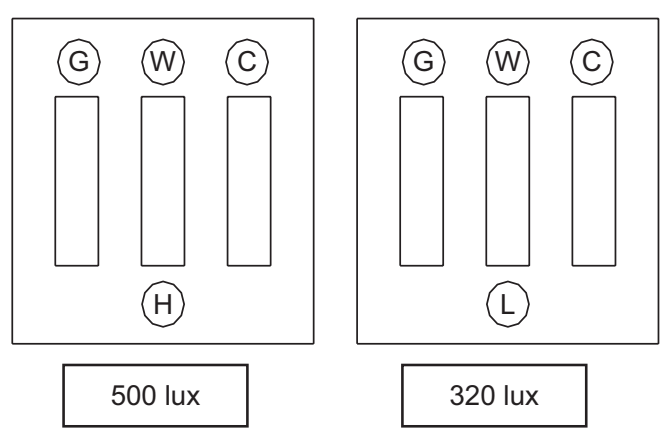

Fig. 8. Drawings of the switch boxes "H" and "L".

Table 1

Surface luminances of the experiment room measured with Minolta LS100 luminance meter

\begin{tabular}{lllllll}
\hline & Wall 1 & Wall 2 & Wall 3 & Wall 4 & Floor & Ceiling \\
\hline General lighting & 50 & 51 & 52 & 53 & 13 & 60 \\
Wall washing & 55 & 61 & 65 & 67 & 10 & 40 \\
Cove lighting & 52 & 53 & 53 & 54 & 12 & 76 \\
Mean values & 52 & 55 & 57 & 58 & 12 & 59 \\
\hline
\end{tabular}

Walls are indicated in Fig. 1 and all measurements are in $\mathrm{cd} / \mathrm{m}^{2}$.

The questionnaire was answered in two stages. In the first stage, the participants were asked to select the most suitable lighting arrangement for each impression (clarity, spaciousness, relaxation, privacy, pleasantness and order) under the 500 lux illuminance (high level). In the second stage, they were asked to compare the two illuminances
(500 and 320 lux) for the lighting arrangement they selected in the first stage. They were asked to choose the more suitable illuminance for the impression under question.

The participants controlled the switches. Adaptation time to lighting systems was not considered a problem as adaptation is mainly affected by illuminance that was the same for all three lighting arrangements. However, when the participants were assessing between illuminances of the same lighting arrangement, they were asked to wait about $1 \mathrm{~min}$ before the assessment for visual adaptation.

In the given questionnaire, $36 \%$ of the participants indicated they had an eye defect. The eye deficiencies reported were: myopia $11 \%$, hypermetropia $8 \%$, astigmatism 5\%, myopia and astigmatism combined $6 \%$, hypermetropia and astigmatism combined $4 \%$ and colour blindness $2 \%$. There was no participant with severe eye defects. Participants with eye defects were asked to take the test with their correction equipment, namely glasses or contact lenses.

\section{Data analysis}

The hypotheses were tested statistically based on the data obtained.

Chi-square $\left(\chi^{2}\right)$ test was conducted to find out whether there is a significant relationship between the lighting arrangements (general lighting, cove lighting and wall washing) and different impressions. Furthermore, for each pair of lighting arrangements on each impression, proportion $(p)$ of preferences was tested using single-sample proportion test for large samples. In all these tests:

Ho $: p=1 / 2$,

Ha $: p>1 / 2$.

Thus, based on the observed proportions obtained from the data, for each impression the claim of the proportion of preferences on one of the two lighting arrangements is higher, was tested.

To analyse the effect of illuminances on the preferred lighting arrangements for each impression, single sample proportion test was conducted. This test was used to find out whether there were certain more significant preferences of illuminances that are thought to be more suitable for preferred lighting arrangement of each impression by making pair-wise comparisons.

Thus, for given impression and preferred lighting arrangement, based on the observed proportion of preferences of illuminances, the hypothesis of proportion of one of the two illuminances is higher $(p>1 / 2)$, was tested.

\section{Findings and discussion}

From the results of the chi-square test it can be concluded that lighting arrangements significantly effect impressions of people about a room $(p$-value $=0.0000)$. 
Table 2

The questionnaire

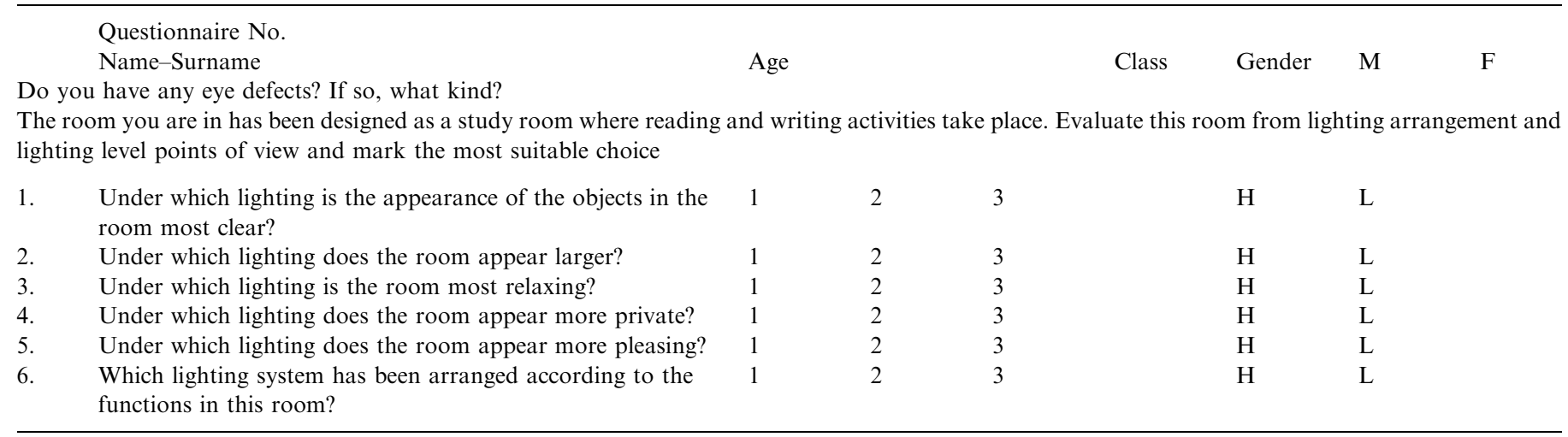

The results of lighting preferences for each impression are as follows:

\subsection{Clarity}

Clarity was tested with the first question of the questionnaire. In clarity, people preferred general lighting $(p$-value $=0.0002)$ and wall washing $(p$-value $=0.0002)$ over cove lighting, but there was no significant difference between preferring general lighting and wall washing $(p$-value $=0.9204)$. For both general lighting and wall washing people preferred them to be at high level, 500 lux, to enhance clarity ( $p$-value $=0.0002$ for each).

\subsection{Spaciousness}

Spaciousness was tested with the second question of the questionnaire. In spaciousness, wall washing was preferred the most. Wall washing was preferred more than general lighting $(p$-value $=0.0178)$ and more than cove lighting $(p$-value $=0.0002)$. To enhance spaciousness people preferred wall washing to be of high level, 500 lux ( $p$ value $=0.0002$ ).

\subsection{Relaxation}

Relaxation was tested with the third question of the questionnaire. In relaxation, cove lighting was preferred the most. Cove lighting was preferred more than general lighting $(p$-value $=0.0002$ ) and more than wall washing ( $p$-value $=0.0096)$. To enhance relaxation people preferred cove lighting to be of low level, 320 lux ( $p$-value $=0.0016$ ).

\subsection{Privacy}

Privacy was tested with the fourth question of the questionnaire. In privacy, cove lighting was preferred the most. Cove lighting was preferred more than general lighting ( $p$-value $=0.0002$ ) and more than wall washing $(p$-value $=0.0002)$. Cove lighting was preferred to be at low lighting level (320lux) to achieve privacy ( $p$-value $=$ 0.0002).

When all the surfaces around the participants are compared from Table 1, it is seen that the wall surfaces received the least light under cove lighting. Being surrounded by less bright walls in the line of sight was enhancing the impression of privacy.

\subsection{Pleasantness}

Pleasantness was tested with the fifth question of the questionnaire. For pleasantness, people preferred cove lighting ( $p$-value $=0.0002)$ and wall washing $(p$-value $=$ 0.0002 ) over general lighting, but there was no significant difference between preferring cove lighting and wall washing ( $p$-value $=0.215$ )

For both cove lighting and wall washing people did not prefer one illuminance level to the other. Thus, there was no difference between high (500lux) and low (320lux) illuminances for the impression of pleasantness ( $p$-value $=$ 0.6242 for cove lighting, $p$-value $=0.215$ for wall washing). People enjoyed both illuminances.

\subsection{Order}

Order was tested with the sixth question of the questionnaire. Visual order is closely related to the unification of the lighting arrangement with the activities in the room. For achieving visual order people preferred wall washing the most. Wall washing was preferred more than general lighting $(p$-value $=0.0016)$ and more than cove lighting ( $p$-value $=0.0002)$. Wall washing was preferred to be at high illuminance level, 500 lux, to achieve visual order $(p$-value $=0.0038)$.

\section{Conclusion}

Hypothesis 1. The result of the chi-square test showed that impressions for different lighting arrangements were statistically differentiated from each other. Therefore, the 
Table 3

Lighting arrangements and illuminances preferred for each impression

\begin{tabular}{lll}
\hline Impression & Lighting arrangement & Illuminance \\
\hline Clarity & $\begin{array}{l}\text { General lighting and } \\
\text { Wall washing }\end{array}$ & High (500 lux) \\
Spaciousness & Wall washing & High (500 lux) \\
Relaxation & Cove lighting & Low (320 lux) \\
Privacy & Cove lighting & Low (320lux) \\
Pleasantness & Cove lighting and wall & High (500 lux) and low \\
& washing & (320lux) \\
Order & Wall washing & High (500 lux) \\
\hline
\end{tabular}

first hypothesis is supported. It can be concluded that different lighting arrangements effect impressions of people about a room $(p$-value $=0.0000)$. Table 3 shows the lighting arrangements preferred for each impression.

Hypothesis 2. To analyse the effect of illuminances on the preferred lighting arrangements for each impression, single sample proportion test was conducted. The test showed that there is a statistically significant difference between the number of people preferring high and low levels of illumination for the lighting arrangements they chose for a specific impression. Therefore, the second hypothesis is also supported. It can be concluded that different illuminances of the same lighting arrangement effect impressions of people about a room. Table 3 shows the illuminances preferred for each impression.

Lighting can effect the mood setting in a space by arousing different impressions with the use of different lighting arrangements at different illuminances. In this study, wall washing and cove lighting were preferred lighting arrangements to convey different impressions. General lighting was only found to be preferred to obtain clarity. Wall washing was associated with the impressions of clarity, spaciousness, pleasantness and order, while cove lighting was associated with relaxation, privacy and pleasantness. Wall washing was always preferred to be at high illuminance, 500 lux, and cove lighting to be at low illuminance, 320 lux.

In many everyday spaces, from houses to offices, from schools to hospitals, general lighting is most widely used. This experiment shows that wall washing and cove lighting are preferred over general lighting to improve the visual quality of space, to make spaces appear clear, spacious, relaxing, private, pleasant and orderly.

\section{References}

[1] Flynn JE, Spencer TJ, Martyniuk O, Hendrick C. Interim study of procedures for investigating the effect of light on impression and behaviour. Journal of the Illuminating Engineering Society 1973;3(2):87-94.

[2] Flynn JE. A study of subjective responses to low energy and nonuniform lighting systems. Lighting Design and Application 1977;7:6-15.

[3] Flynn JE, Spencer TJ. The effects of light source color on user impression and satisfaction. Journal of the Illuminating Engineering Society $1977 ; 6: 167-79$.

[4] Flynn JE, Hendrick C, Spencer TJ, Martyniuk O. A guide to the methodology procedures for measuring subjective impressions in lighting. Journal of the Illuminating Engineering Society 1979;8:95-110.

[5] Mehrabian A, Russel J. An approach to environmental psychology. Cambridge, MA: MIT Press; 1974. p. 18.

[6] İmamoğlu V. Spaciousness of interiors: its meaning, measurement and relationship to some architectural variables. Unpublished dissertation. Strathclyde University; 1975. p. 8-10.

[7] İmamoğlu V. Spaciousness and interior design. In: Proceedings of the symposium on furnishing and design of interiors. Ankara: Hacettepe University; 1987 p. 33, 40,[in Turkish].

[8] Nuckolls JL. Interior lighting for environmental designers, second ed. New York: Wiley; 1983. p. 4, 40, 354.

[9] Erhardt L. Views on the visual environment. New York: Illuminating Engineering Society of North America; 1985. p. 13, 23, 30.

[10] Tiller DK, Veitch J. Perceived room brightness: pilot study on the effect of luminance distribution. Lighting Research and Technology 1995;27(2):93-101.

[11] Sorcar PC. Architectural lighting for commercial interiors. New York: Wiley; 1987. p. 158-166, 178-181.

[12] Smith FK, Bertolone FJ. Bringing interiors to light. New York: Watson-Guptill; 1986. p. 26.

[13] Smith FK. Spaciousness. Lighting Design and Application 1989:18-23.

[14] Steffy GR. Architectural lighting design. New York: Van Nostrand Reinhold Co.; 1990. p. 5, 20, 30-37, 55-60, 101.

[15] Rea MS. Selected papers on architectural lighting. SPIE milestone series, vol. MS58. Washington: SPIE Optical Engineering Press; 1992. p. $435-442,502$.

[16] Carmondy J, Sterling R. Underground space design. New York: Van Nostrand Reinhold; 1993. p. 265, 276.

[17] Lou M. Light: the shape of space. New York: Van Nostrand Reinhold; 1996. p. 177, 178, 181, 182, 189.

[18] Manav B, Yener C. Effects of different lighting arrangements on space perception. Architectural Science Review 1999;42(1):43-8.

[19] International Organization for Standardization. ISO 8995, principles of visual engineering ergonomics. Geneva: International Organization for Standards; 1989.

[20] International Commission on Illumination. Guide on interior lighting, no:29 (TC-4.1), second ed. New York: Commission International de L'Eclairage; 1986.

[21] Philips Lighting. Lighting manual. Eindhoven: Philips Lighting; 1993.

[22] Illuminating Engineering Society of North America. IES lighting handbook. New York: Illumination Engineering Society of North America; 1987. p. 1, 32. 